\section{Outbreak of Hand, Foot, and Mouth Disease Caused by Coxsackievirus A6 Among Basic Military Trainees - Texas, 2015}

Jonathan Banta, MD ${ }^{1}$; Brittany Lenz, MD²; Mary Pawlak, $\mathrm{MD}^{3}$; Kelly Laskoski, $\mathrm{MD}^{4}$; Caitlin Seykora, $\mathrm{DO}^{2}$; Bryant Webber, $\mathrm{MD}^{3}$; Heather Yun, $\mathrm{MD}^{1}$; Simon Ritchie, $\mathrm{MD}^{2}$

On July 7, 2015, a man aged 22 years reported to sick call during basic military training at Lackland Air Force Base (AFB), Texas. He had erythematous, crusted papulovesicular lesions on the extensor surfaces of the upper and lower extremities. The patient was afebrile and otherwise well, and was evaluated later that day by the dermatology service. A viral infection was considered most likely because of the patient's age, absence of fever or constitutional symptoms, and the distribution and morphology of the lesions. The initial differential diagnosis included HenochSchönlein purpura, parvovirus B19, and Rocky Mountain spotted fever. However, the clinical signs, including the unique morphology and distribution of grouped vesicles and papules was suggestive of hand, foot, and mouth disease (HFMD), although the patient did not have oral lesions and reported no contact with another person with HFMD. A viral culture and punch biopsy of one of the lesions were obtained.

On July 8, another patient with similar complaints was evaluated at the clinic, and by September 18, a total of 53 patients had been evaluated (Figure 1). Ten patients, who had extensive involvement of the face, forearms, and lower extremities (Figure 2), were evaluated in the dermatology clinic. Prodromal symptoms of fever and malaise were reported by $11 \%$ and $96 \%$ of patients, respectively; these symptoms were typically followed by erosive stomatitis and a rash that began on the palms and soles. Patients ranged in age from 18 to 33 years (mean $=21$ years the overall average age of basic trainee population]). Forty-eight (91\%) patients were male (overall, approximately $77 \%$ of all trainees are male).

A suspected case of HFMD was defined as the occurrence of multiple erythematous papulovesicular lesions on the legs, arms, face, or oral mucosa in a person involved in basic military training activities at Lackland AFB during July 6-September 18. A confirmed case was defined as an illness meeting the clinical case definition with laboratory identification of an enterovirus.

FIGURE 1. Confirmed and suspected cases of hand, foot, and mouth disease, by date of symptom onset and patients' military classification Lackland Air Force Base, Texas, July 6-September 18, 2015

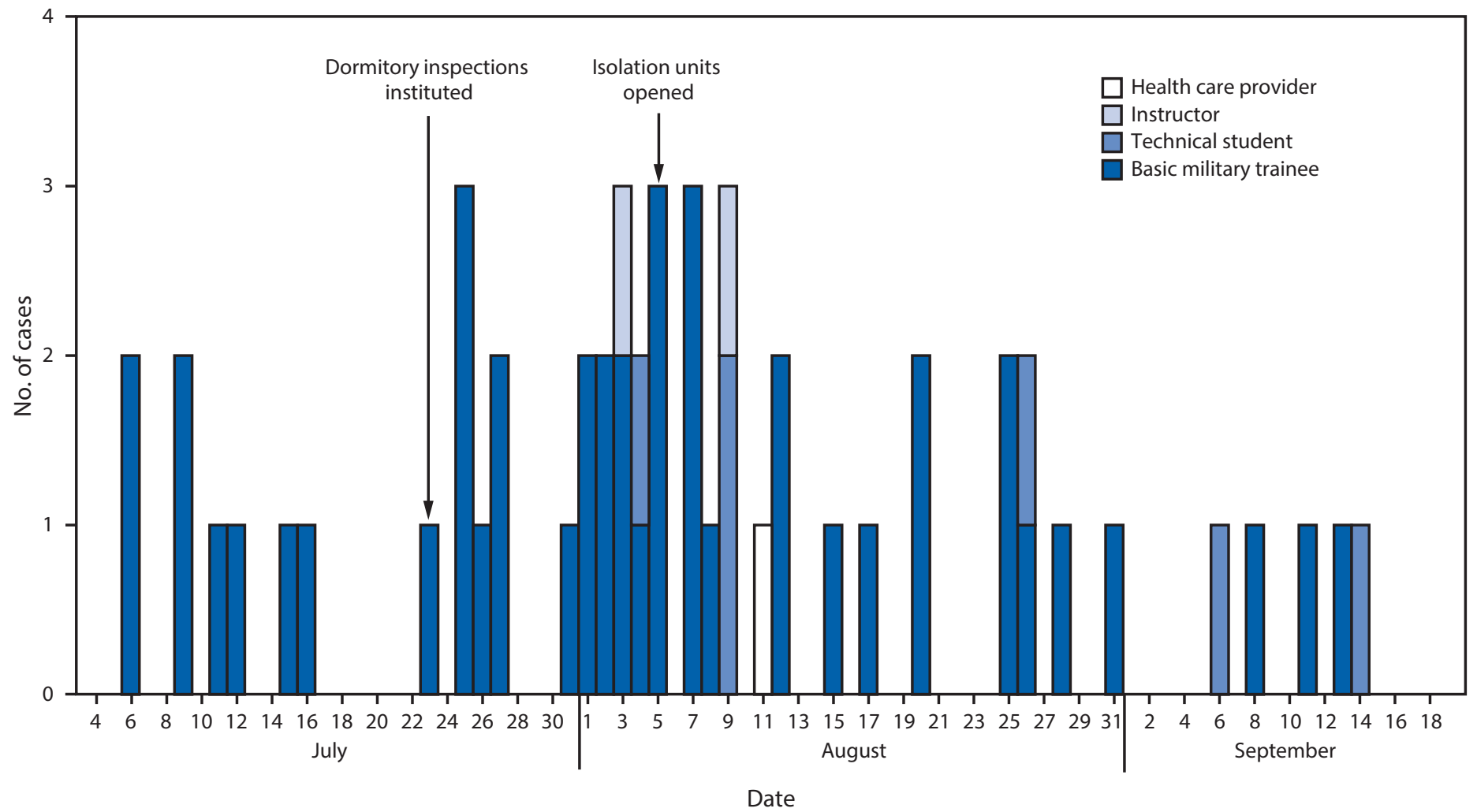


FIGURE 2. Dermatologic and mucosal manifestations of hand, foot, and mouth disease among military personnel, demonstrating (A) extensive and confluent purpuric and hemorrhagic crusted papules and plaques on the foot and anterior shin; (B) erythematous papules and erosions on the palate; (C) grouped purpuric papules on the hand; and (D) similar lesions with extensive involvement of the extensor aspects of the upper extremities - Lackland Air Force Base, Texas, July 6-September 18, 2015

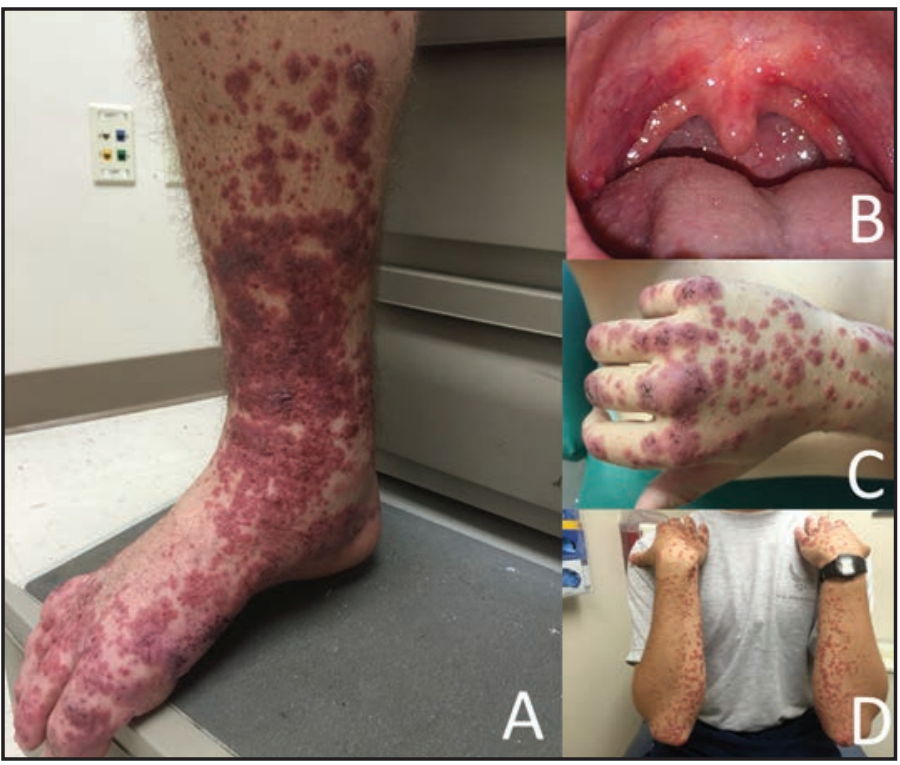

Fifty-three cases (eight confirmed, 45 suspected) were identified in 44 basic military trainees, six recent graduates, two instructors, and one health care provider (Figure 1). Patients were initially identified through provider reporting. However, once the outbreak was recognized, some patients did not receive a referral for a dermatology or infectious diseases consultation; these patients were later identified through a retrospective record review of the electronic health record for all patients on the installation. This method most likely captured all cases of HFMD occurring on the installation during the defined period: basic trainees are in a closed environment under strict supervision, and all basic training instructors were directed to have any trainee displaying symptoms be seen by a provider on base. Eight of 12 nasopharyngeal specimens tested locally by reverse transcription-polymerase chain reaction (RT-PCR) were positive for enterovirus. Five enterovirus-positive specimens were tested by pan-enterovirus viral protein 1 (VP1) RT-PCR, followed by Sanger sequencing of four of five positive specimens at CDC. Bioinformatic analysis of the sequences identified coxsackievirus A6 (CVA6) in all four nasopharyngeal specimens. The rate of infection was $0.4 \%$ (50 of 12,270 persons) in the basic training population and $0.3 \%$ (two of 602 persons) among instructors. After accounting for clustering (i.e., restricting the population at risk for HFMD to persons in training subunits that experienced cases), the rate of infection among trainees was $4.7 \%$ (50 of 1,054 persons).

HFMD typically occurs in children in the United States during summer and autumn. Clinical manifestations usually begin with fever and malaise and can progress to painful oral lesions and a rash involving the hands and feet; infected adults often are asymptomatic. Although coxsackievirus A16 has historically been the primary etiologic agent of HFMD in the United States, CVA6 has emerged as the cause in many recently reported outbreaks (1-5). Young adults appear to be more susceptible to infection with CVA6, which causes atypical perioral eruptions and skin manifestations that extend beyond the palmar and plantar surfaces (1). Military trainees are particularly vulnerable to communicable diseases, because of close living and sleeping arrangements, physical and mental stressors, and substandard hygiene (G). Transmission of CVA6 occurs through contact with a patient's respiratory secretions, scabs, vesicle fluid, and feces, and through contact with fomites (7).

After the first five cases were identified, steps were taken to limit spread and minimize lost training days by providing education about the signs and symptoms of HFMD and the importance of seeking care if symptoms developed. Surgical masks were issued to trainees with suspected HFMD (8), who also slept in separate bedrooms and dined apart from other trainees. Public health personnel inspected all affected living quarters and training sites (Figure 1) and made recommendations regarding hygiene (9); the clinical response was coordinated among all providers who might evaluate new cases. Clinics were advised to issue face masks to all patients suspected to be infected with HFMD. Cases continued to be reported for weeks after these interventions (Figure 1), but the disease was confined to $20(17 \%)$ of the 117 basic military training units on the installation during the outbreak period. All 53 cases resolved spontaneously with supportive therapy; none required hospitalization. HFMD infection is primarily determined by clinical diagnosis because CVA6 is a fastidious enterovirus and typically does not easily grow in culture; VP1 RT-PCR followed by sequencing and sequence analysis can be used to confirm the diagnosis (10). Measures to prevent transmission should be implemented as soon as clinical suspicion of the disease occurs.

\footnotetext{
${ }^{1}$ San Antonio Military Medical Center, Fort Sam Houston, Texas; ${ }^{2}$ Wilford Hall Ambulatory Surgical Center, Lackland Air Force Base, Texas; ${ }^{3}$ Trainee Health Surveillance, 559th Medical Group, Lackland Air Force Base, Texas; ${ }^{4}$ Aerospace Medicine Squadron, 559th Medical Group, Lackland Air Force Base, Texas.

Corresponding author: Simon Ritchie, simon.ritchie@us.af.mil, 301-704-9743.
} 


\section{References}

1. Bian L, Wang Y, Yao X, Mao Q, Xu M, Liang Z. Coxsackievirus A6: a new emerging pathogen causing hand, foot and mouth disease outbreaks worldwide. Expert Rev Anti Infect Ther 2015;13:1061-71. http://dx.doi. org/10.1586/14787210.2015.1058156

2. Buttery VW, Kenyon C, Grunewald S, Oberste MS, Nix WA. Notes from the field: atypical presentations of hand, foot, and mouth disease caused by coxsackievirus A6-Minnesota, 2014. MMWR Morb Mortal Wkly Rep 2015;64:805. http://dx.doi.org/10.15585/mmwr.mm6429a8

3. Puenpa J, Chieochansin T, Linsuwanon P, et al. Hand, foot, and mouth disease caused by coxsackievirus A6, Thailand, 2012. Emerg Infect Dis 2013;19:641-3. http://dx.doi.org/10.3201/eid1904.121666

4. Flett K, Youngster I, Huang J, et al. Hand, foot, and mouth disease caused by coxsackievirus A6. Emerg Infect Dis 2012;18:1702-4. http://dx.doi. org/10.3201/eid 1810.120813

5. CDC. Notes from the field: severe hand, foot, and mouth disease associated with coxsackievirus A6-Alabama, Connecticut, California, and Nevada, November 2011-February 2012. MMWR Morb Mortal Wkly Rep 2012;61:213-4.
6. Brundage JF, Scott RM, Lednar WM, Smith DW, Miller RN. Buildingassociated risk of febrile acute respiratory diseases in Army trainees. JAMA 1988;259:2108-12. http://dx.doi.org/10.1001/jama.1988.03720140028029

7. Romero JR, Modlin JF. Introduction to the human enteroviruses and parechoviruses. In: Bennett JE, Dolin R, Blaser MJ, eds. Mandell, Douglas, and Bennet's principles and practice of infectious diseases. 8th ed. Philadelphia, PA: Saunders; 2014.

8. Jefferson T, Del Mar C, Dooley L, et al. Physical interventions to interrupt or reduce the spread of respiratory viruses: systematic review. BMJ 2009;339:b3675. http://dx.doi.org/10.1136/bmj.b3675

9. Ruan F, Yang T, Ma H, et al. Risk factors for hand, foot, and mouth disease and herpangina and the preventive effect of hand-washing. Pediatrics 2011;127:e898-904. http://dx.doi.org/10.1542/peds.2010-1497

10. Nix WA, Oberste MS, Pallansch MA. Sensitive, seminested PCR amplification of VP1 sequences for direct identification of all enterovirus serotypes from original clinical specimens. J Clin Microbiol 2006;44:2698-704. http://dx.doi.org/10.1128/JCM.00542-06 